\title{
Bacteriological Profile of Community Acquired Pneumonia
}

\author{
Dr.Mythri.S ${ }^{1}$, Dr. Nataraju.H.V ${ }^{2}$ \\ 1. Post Graduate Student, Dept. Of General Medicine, Kempegowda Institute of Medical Sciences, Bangalore. \\ 2. Professor\& HOD, Dept. Of General Medicine, Kempegowda Instituteof Medical Sciences, Bangalore
}

\begin{abstract}
Introduction: Community acquired pneumonia (CAP) is a common health problem seen in all age groups. The risk increases with increase in the age. It has very high morbidity and mortality. Smokings, COPD, older age are risk factors for CAP. Gram negative organisms are more commonly associated with older age. Once the culture reports are obtained, the treatment has to be changed according to the identified organism.

Aim: To determine common aetiological (bacterial) agents for CAP in adults from sputum samples.

Methods:Sputum samples are obtained for culture. The sputum was inoculated on Mac Conkey's agar, sheep Blood agar \& Chocolate agar. Blood was inoculated into BHI broth and subculture was done on alternate days for 7 days. The isolates were identified by Gram's stain and biochemical tests.

Results: Out of 100 cases, the isolation rate was $72 \%$ from Sputum culture. The culture predominantly yielded Klebsiellaspp followed by S.pneumoniae.

Conclusion: Gram's staining is the initial screening test. Sputum culture helps to a great extent in the diagnosis and treatment.
\end{abstract}

Key words: Community acquired pneumonia, sputum culture, bacteria.

\section{Introduction:}

Community-acquired pneumonia (CAP) is one of the most common infectious diseases addressed by clinicians. CAP is an important cause of mortality and morbidity worldwide.

A number of pathogens can give rise to CAP. Typical bacterial pathogens that cause the condition include Streptococcuspneumoniae (penicillin-sensitiveandresistantstrains), Haemophilusinfluenzae (ampicillinsensitive and -resistant strains), and Moraxella catarrhalis (all strains penicillin-resistant). These 3 pathogens account for approximately $85 \%$ of CAP cases.

CAP is usually acquired via inhalation or aspiration of pulmonary pathogenic organisms into a lung segment or lobe.

Less commonly, CAP results from secondary bacteraemia from a distant source, such as Escherichia coli urinary tract infection and/or bacteraemia.

Aspiration pneumonia is the only form of CAP caused by multiple pathogens (e.g., aerobic/anaerobic oral organisms).

CAP morbidity and mortality are highest in elderly patients and in immunocompromised hosts.

There are over a hundred microorganisms which can cause CAP. The most common types of microorganisms are different among different groups of people. Newborn infants, children, and adults are at risk for different spectrums of disease causing microorganisms. In addition, adults with chronic illnesses, who live in certain parts of the world, who reside in nursing homes, who have recently been treated with antibiotics, or who are alcoholics are at risk for unique infections. Even when aggressive measures are taken, a definite cause for pneumonia is only identified in half the cases.

CAP can be diagnosed by symptoms and physical examination alone, though x-rays, examination of the sputum, and other tests are often used.

The majority of patients with CAP are treated empirically based on the most common pathogen(s) associated with the condition. But an increase in the prevalence of drug resistance to antibiotics among common pathogens has been recognized as a problem[1].Hence, it is required to document the initial antibiotic choice based on the common pathogens isolated and antimicrobial resistance patterns in that community.

Aim: To determine common aetiological (bacterial) agents for CAP in adults from sputum samples.

\section{Methodology:}

100 cases were selected from the patients attending the Medicine out-patient and in-patient departments of Kempegowda Institute of Medical Sciences, Bangalore.

Inclusion criteria:

1. A new pulmonary infiltration on chest roentgenogram on admission or within $24 \mathrm{hrs}$. 
2. Clinical findings:

Major criteria- Cough, sputum production, or fever $>37.8^{\circ} \mathrm{C}$

Minor criteria- Pleuritic chest pain, dyspnea, altered mental status, pulmonary consolidation by examination,

WBC count $>11,000 / \mathrm{mm}^{3}$.

For confirmation atleast 1 of the major criteria or 2 of the minor criteria need to be present.

\section{Exclusion criteria}

1. Patients with previous admission in either a private resident or a nursing home. Patients with a previous hospitalization or transfer from another hospital within 7 days of the current diagnosis of pneumonia.

2. Patients in whom chest roentgenogram abnormalities were attributed to congestive heart failure, pulmonary embolism or chronic underlying lung disease. [1]

Method of study - Cross Sectional Observational Clinical Study

Sputum collection:Early morning deeply coughed out sputum was collected in a sterile wide mouthed container.

Sputum: Gram's stain was done and looked for pus cells, epithelial cells and bacteria. Those specimen with $>25$ pus cells were put into culture. The specimen was inoculated on Mac Conkey's agar, sheep Blood agar and Chocolate agar and incubated at $37^{\circ} \mathrm{C}$ for $18-24 \mathrm{hrs}$. The growth was subjected to Gram's staining and biochemical tests for identification.

Statistical methods: Chi-square/ Fisher Exact test has been used to find the significance of study parameters on categorical scale between two or more groups.

III. Results:

Table 1: Gram's stain

\begin{tabular}{|ll|l|l|}
\hline Gram's stain & $\begin{array}{l}\text { Number } \\
\text { patients } \\
(\mathbf{n = 7 2 )}\end{array}$ & $\%$ \\
\hline $\begin{array}{l}>25 \\
<10 \mathrm{EC} / \mathrm{LPF}\end{array}$ & PC & 58 & $80.5 \%$ \\
\hline $\begin{array}{l}>25 \\
>10 \mathrm{EC} / \mathrm{LPF}\end{array}$ & PC & 14 & $19.4 \%$ \\
\hline Not done & 28 & - \\
\hline
\end{tabular}

*Sputum could not be obtained in 28 patients

Table 2: Sputum culture

\begin{tabular}{|c|l|l|}
\hline Sputum culture & $\begin{array}{l}\text { Number of patients } \\
(\mathbf{n = 7 2 )}\end{array}$ & \% of organisms isolated \\
\hline Normal Commensals & 34 & - \\
\hline Organisms Isolated & 38 & 100.0 \\
\hline Klebsiellaspp & 21 & 55.26 \\
\hline S.pneumoniae & 10 & 26.3 \\
\hline Pseudomonas spp & 4 & 10.5 \\
\hline E.coli & 1 & 2.6 \\
\hline S.aureus & 1 & 2.6 \\
\hline NFGNB & 1 & 2.6 \\
\hline
\end{tabular}

Note: 2 patients samples shown isolation of 2 pathogens 


\section{Graph No.1 Sputum culture results}

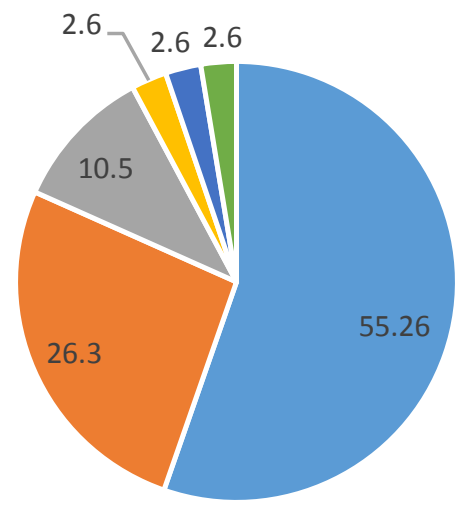

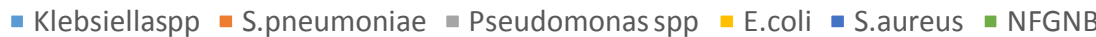

\section{Gram's stain:}

\section{Discussion:}

Sputum Gram's stain is necessary to check the suitability of the specimen for culture. The present study shows higher rate of isolation of potential pathogens in the specimens containing $>25$ pus cells and $<10$ epithelial cells per LPF as compared to specimens containing $>25$ pus cells and $>10$ epithelial cells per LPF. This shows that isolating potential pathogens increases markedly when the specimen contains fewer epithelial cells. The study is consistent with the study of Manolito L. Chua et al 1996[2]

In the present study, aetiology was achieved only in 38 cases $(38 \%)$. The low rate of isolation could be due to non-availability of sputum in all cases $(28 \%)$, prior antibiotic administration, and lack of availability of serological methods for the detection of Mycoplasma, Chlamydia, Legionella and viruses.

In the present study the most common organism isolated was Klebsiellaspp followed by S.pneumoniae and Pseudomonas spp. Indian studies over the last three decades have reported higher incidence of gram negative organisms among culture positive pneumonia[3.4] While few studies from India, U.S. and UK also reported that $\mathrm{S}$. pneumoniae as the common isolated pathogen in $20-35 \%$ of cases. $[5,6,7,8]$

\section{Conclusion:}

Identification of the specific pathogen in acute bacterial pneumonia is necessary for rational and appropriate antibiotic therapy.

In this study the sputum culture yielded the isolation of potential pathogens in $54.5 \%$ cases. Chancesof isolation from sputum is more if the specimen under Gram's stain shows $>25$ pus cells and $<10$ epithelial cells per LPF.

Klebsiella species is the most common organism isolated followed by S.pneumoniae

\section{References:}

[1]. Harrison's principles of internal medicine. Edition 18.Chapter 257

[2]. L. Manolito, Chua, M.D., C. Marie Yvette Barez, M.D., Marlene Santos, M.D., C. Cristina Pineda, R.M.T. and T. Myrna. Mendoza, M.D. The value of Prompt Culture of an Adequate Sputum Specimen in Predicting the Potential Etiology of Community-Acquired Pneumonia. Phil J Microbiol Infect Dis 1996; 25(1): 13-17.

[3]. S.V.Madhu, Umesh Gupta, J.S. Guleria, V.Talwar. Clinical and Bacteriological Profile of Hospitalized Community Acquired Pneumonias. Indian J Chest Dis \& All Sci. 1990; 32 (2) : 95-100.

[4]. D.D.S Kulpati and Adarsh Kumar. Flexible Fiberoptic Bronchoscopy in Lower Respiratory Tract Infection. Indian J Chest Dis \& All Sci, Sep. 1979; 39-46.

[5]. S. Bansal, S. Kashyap, L.S. Pal and A. Goel. Clinical and Bacteriological Profile of Community Acquired Pneumonia in Shimla, Himachal Pradesh. Indian J Chest Dis Allied Sci 2004; 46:17-22.

[6]. Aroma Oberoi, Aruna Aggarwal. Bacteriological Profile, Serology and Antibiotic Sensitivity Pattern of Micro-organisms from Community Acquired Pneumonia. J K Science April-June 2006; 8(2): 79-82.

[7]. J Macfarlane, W. Holmes, P Gard, R Macfarlane, D Rose, V Weston, et al. Prospective study of the incidence, aetiology and outcome of adult lower respiratory tract illness in the community. Thorax.2001; 56:109-114.

[8]. Gene Ong, M.D., Melecia Antonio-Velmonte, M.D., T. Myrna Mendoza, M.D. Etiologic Agents of Community-Acquired Pneumonia in the Adult: The PGH Experience. Phil J Microbial Infect Dis.1995; 24(2): 29-32. 
